\title{
Genetic causes of recurrent miscarriages
}

\author{
Marta Kacprzak ${ }^{1}$, Marta Chrzanowska ${ }^{1}$, Beata Skoczylas², Hanna Moczulska ${ }^{2,3}$, \\ Maciej Borowiec ${ }^{2,}{ }^{3}$, Piotr Sieroszewski ${ }^{1}$ \\ ${ }^{1}$ Department of Fetal Medicine and Gynecology, Medical University of Lodz, Poland \\ ${ }^{2}$ Department of Clinical Genetics, Central Clinical Hospital of the Medical University of Lodz, Poland \\ ${ }^{3}$ Department of Clinical and Laboratory Genetics, Medical University of Lodz, Poland
}

\begin{abstract}
Recurrent miscarriage is an important problem in reproductive health, which affects $1-5 \%$ of couples. The aim of this article is to summarize current knowledge on the genetic causes of recurrent miscarriage. It presents the most common parental genetic disorders (karyotype abnormalities, recessive diseases carrier status, dominant diseases and thrombophilia) connected with recurrent pregnancy loss, as well as research into other possible genetic causes. This review also sets out to demonstrate changes in the embryonic/fetal genome that may lead to abortions, and discusses the methods used to assess miscarried material, together with their advantages and disadvantages.

Knowledge of the genetic background of miscarriages is important for prognosis, as well as the potential planning of prenatal diagnostics in subsequent pregnancies.
\end{abstract}

Key words: recurrent miscarriages, chromosome aberrations, genetic causes

Ginekologia Polska 2016; 87, 10: 722-726

\section{INTRODUCTION}

Miscarriage is the most common complication of pregnancy. Although it is estimated to be responsible for ending $10-15 \%$ of clinically diagnosed pregnancies [1], the actual number may be four to five times higher [2]. While the Royal College of Obstetricians and Gynaecologists (RCOG) regard recurrent miscarriages as the loss of three or more successive pregnancies [3, 4], the American Society for Reproductive Medicine defines recurrent miscarriages as at least two successive miscarriages [5]. The problem of recurrent miscarriage is an important one in reproductive health, as it is estimated to affect between one and five percent of couples $[6,7]$. It may have both a genetic and environmental background. The aim of this article is to summarize the current knowledge on the genetic causes of recurrent miscarriage and discuss the role of genetic diagnostics in the determination of the reasons for the pregnancy loss.

Genetic reasons may involve changes in maternal, paternal, or fetal genetic material. Genetic tests may be performed in both parents as well as in the miscarriage material (fetus or afterbirth).

\section{CHANGES IN PARENTAL GENETIC MATERIAL}

Changes in parental (paternal and maternal) genetic material that contribute to the increased risk of miscarriage in successive pregnancies include karyotype abnormalities, recessive and dominant disease carrier status, as well as mutations in genes responsible for coagulation and the metabolism of folates. The presence of karyotype abnormalities in one of the parents is one of the most common of the known causes of recurrent miscarriages. They are most commonly found as balanced chromosome aberrations, i.e. abnormalities that cause no clinical symptoms in carriers but possibly induce the production of abnormal reproductive cells containing abnormal amounts of genetic material. Among couples with recurrent miscarriages, balanced translocations are confirmed in at least one of the partners in around $3 \%$ to $5 \%$ of cases [8-10]. Most commonly, these include reciprocal translocations, with inversions and Robertsonian translocations being less common. The status of a balanced chromosome aberration carrier increases the risk of miscarriage in subsequent pregnancies, as well as the risk of the child being born with an unbalanced karyo- 
type. However, with the exception of some rare cases, most carriers of balanced chromosome aberrations have a good chance of bearing healthy progeny. The risk of miscarriage recurring upon subsequent pregnancy or the risk of the child being born with a karyotype abnormality vary with regard to the type of chromosome aberration. Genetic diagnosis is performed by assessing both parental karyotypes using conventional cytogenetic methods based on light microscopy.

Recessive diseases may be induced by the presence of mutations responsible for single-gene recessive diseases in both of the parents, particularly when the parents are close of kin. An example of such a disease is congenital methemoglobinemia, as described by Kedar et al. [11]. Other examples include the carrier status of mutations responsible for congenital arthrogryposis or Smith-Lemli-Opitz syndrome. Interestingly, the incidence of Smith-Lemli-Opitz syndrome is lower than predicted, which may be attributed to a lack of awareness of the wide spectrum of fetal defects associated with SLO syndrome among obstetricians [12]. If the genetic problem is an autosomal recessive disease, the risk of abnormality recurring in the successive pregnancy is high, amounting to $25 \%$. In real clinical practice, however, it is very difficult to plan diagnostic screening for recessive disease carrier status.

Another group of disorders is composed of autosomal dominant diseases which are transferred to the progeny with a high probability (50\%). Symptoms of these diseases may intensify in subsequent generations (anticipation), as exemplified by myotonic dystrophy, a disease affecting mainly the muscular system, and which is associated with myotonia, muscle stiffness, disturbed speech and swallowing. Myotonia may lead to obstetric complications including miscarriages, preterm birth, edemas, intrauterine fetal demise (stillbirth), prolonged labor or intrapartum hemorrhages. In most cases, no such symptoms are observed in ancestors. Mytonic dystrophy may be suspected, for example, when the family history includes cataract at young age. In such cases, an assessment of fetal development is particularly important, since the disease may be transferred with anticipation of symptoms in the progeny, particularly if inherited from the mother. Fetal ultrasound scans may show a reduced number of fetal movements and swallowing disturbances, leading to polyhydramnios and club feet [13-15]. Although maternal symptoms may be discrete, mutation may lead to fetal demise or stillbirth.

In the case of homozygotic mutations, IUFD (intrauterine fetal death) is associated with the presence of an autosomal dominant disease in both parents, one example of which is achondroplasia. In such cases, it is feasible to use targeted diagnostics in the parents, who should be offered a thorough clinical examination and analysis of descent, followed by diagnostic molecular tests.
Diseases inherited in patterns linked to the X-chromosome may lead to the IUFD of male fetuses. These include congenital Bloch-Sulzberger disease, Goltz syndrome, Rett syndrome and Aicardi syndrome. As these syndromes are very rare, no routine diagnostic tests are currently recommended for screening.

Another cause of recurrent miscarriages is congenital thrombophilia following damage to the maternal factor $\checkmark$ gene G1691A (Leiden mutation) and prothrombin gene (G20210A mutation). These mutations are well studied and the test is part of the routine diagnostics of recurrent miscarriages. In the case of factor $\mathrm{V}$, both the Leiden mutation G1691A and the T1328C mutation appear to be important in the pathogenesis of recurrent miscarriages, particularly in cases observed before the $7^{\text {th }}$ week of gestation [16]. However, identification of the polymorphism within factor $\checkmark$ gene (Leiden mutation) and prothrombin factor II gene may be an insufficient method of screening for congenital thrombophilia risk factors. Obstetric failures may also be caused by genetically-determined disturbances in the activity of, inter alia, factor VII, factor XIII, or beta-fibrinogen [17-19]. However, no current studies report findings which unambiguously confirm the impact of these factors on recurrent miscarriage.

A relationship has been noted between recurrent miscarriage and paternal congenital thrombophilia. A six-fold greater risk of miscarriage was observed in pairs with paternal factor $\mathrm{V}$ Leiden mutation as compared to a control group [20]. The mechanism of this phenomenon has not yet been appropriately studied.

However other studies report no significant difference in the frequency of specific thrombophilia-responsible mutations in women with a history of at least two miscarriages as compared to those with no pregnancy loss. This may suggest that obstetric failures may be dependent on the total number of individual mutations rather than the presence of individual gene mutations [21].

The impact of mutation within the MTHFR gene, a gene encoding a protein involved in the metabolism of folates, on recurrent miscarriages is currently a matter of debate. Reports suggest no relationship between hyperhomocysteinemia and reproductive failures. This may be due to folic acid supplementation, particularly during the first trimester [22].

Other studies have addressed other genetic causes for obstetric failure. One such disorder connected with the risk of recurrent miscarriage is obesity. There is evidence that $\mathrm{BMI} \geq 30 \mathrm{~kg} / \mathrm{m}^{2}$ is an independent risk factor of spontaneous as well as recurrent abortion [7]. However, it has been reported that even a genetic predisposition to obesity is associated with a greater probability of recurrent pregnancy loss. Sinhalese women who experienced recurrent miscarriages had a significantly higher prevalence of the 
allele variant of the single nucleotide polymorphism (SNP) rs9939609 in the fat and obesity associated gene (FTO) associated with obesity [23].

\section{CHANGES IN EMBRYONIC/FETAL GENETIC MATERIAL}

Another genomic cause of miscarriages is associated with the presence of fetal genetic abnormalities. These may include both de novo changes and changes inherited from one of the parents. The knowledge of whether a particular change is a de novo or inherited change is very important in genetic counseling.

It is estimated that about $50 \%$ of first-trimester pregnancy losses are associated with chromosome aberrations in the developing embryo/fetus [24, 25]. In most cases, these are de novo changes, which means the risk of a similar abnormality occurring during the next pregnancy is low $[26,27]$. Kwinecka-Dmitriew et al. observed a lower percentage of chromosome aberrations in the material collected from successive miscarriage as compared to the first miscarriage, leading to the conclusion that other factors may be responsible for recurring miscarriage [27]. The largest group of abnormalities in embryonic/fetal genetic material consists of aberrations in the number of chromosomes (86\%), mainly autosomal trisomies, monosomy $\mathrm{X}$ and polyploidies. The remaining group included structural aberrations (6\%) and chromosomal mosaicism (8\%) [24]. Fetal autosomal trisomies represent at least $50 \%$ of the chromosomal aberrations responsible for pregnancy loss $[24,25]$. Trisomies may be generally observed in all autosomal chromosomes, although the incidence of particular trisomies varies. The most common trisomies are observed with chromosome 16 followed by chromosome 22. Also frequently encountered are the trisomies of chromosomes $13,15,18$, and 21 [25]. The risk of embryonic/fetal trisomies increases with maternal age [28].

\section{ASSESSMENT OF THE MISCARRIED MATERIAL}

The use of classic cytogenetic examination to assess fetal karyotype in the miscarried material is complicated by the sample being contaminated by maternal tissue and the associated risk of false negative results. The method also depends on the correct performance of cell culturing, which is not always possible in case of miscarried tissue [29].

Genetic analyses of the miscarried material are usually based on molecular biology techniques. Proper collection of the examined sample is important to avoid contamination with maternal tissue. The miscarried material must first be dried and rinsed of blood with physiological saline, before precise isolation of chorionic villi is performed [30]. If the fetal tissues are already well formed and visible, a fragment of the umbilical cord may be used for examination purposes. Miscarried material may also be analyzed in paraffin blocks [31]; such examinations may be carried out several years after the block is prepared [32].

The assessment of the presence of genetic abnormalities within the miscarried material may be based on molecular diagnostic methods such as FISH, MLPA, QF-PCR, BoBs or comparative genomic hybridization $(\mathrm{CGH})$, which allow not only the detection of aneuploidy in fetal tissues but also microdeletions and other unbalanced genomic changes. Some hope is offered by novel diagnostic methods such as next-generation sequencing (NGS), which facilitates the simultaneous examination of all or selected genes, allowing diagnosis and then a choice for further action. An outline of available classic cytogenetics, molecular cytogenetics, and molecular biology techniques used for the examination of embryonic/fetal material is presented in Table 1.

\section{SUMMARY}

Recurrent miscarriages may occur due to a diverse range of causes. Knowledge of the genetic background of miscarriage is very important for prognosis, as well as to plan prenatal diagnostics in subsequent pregnancies. However, it is very difficult to make an appropriate diagnosis, particularly during the early stages of pregnancy. Usually, targeted genomic diagnostics are required following a clinical observation by ultrasound or pathological examination of the fetus.

In as many as $50 \%$ of cases of recurrent miscarriage, none of the known causes may be determined. Therefore, new potential abnormalities, including genetic abnormalities that lead to pregnancy losses, such as a genetic predisposition to obesity, need to be identified, and the methods used for their diagnosis need to be further expanded and refined. 


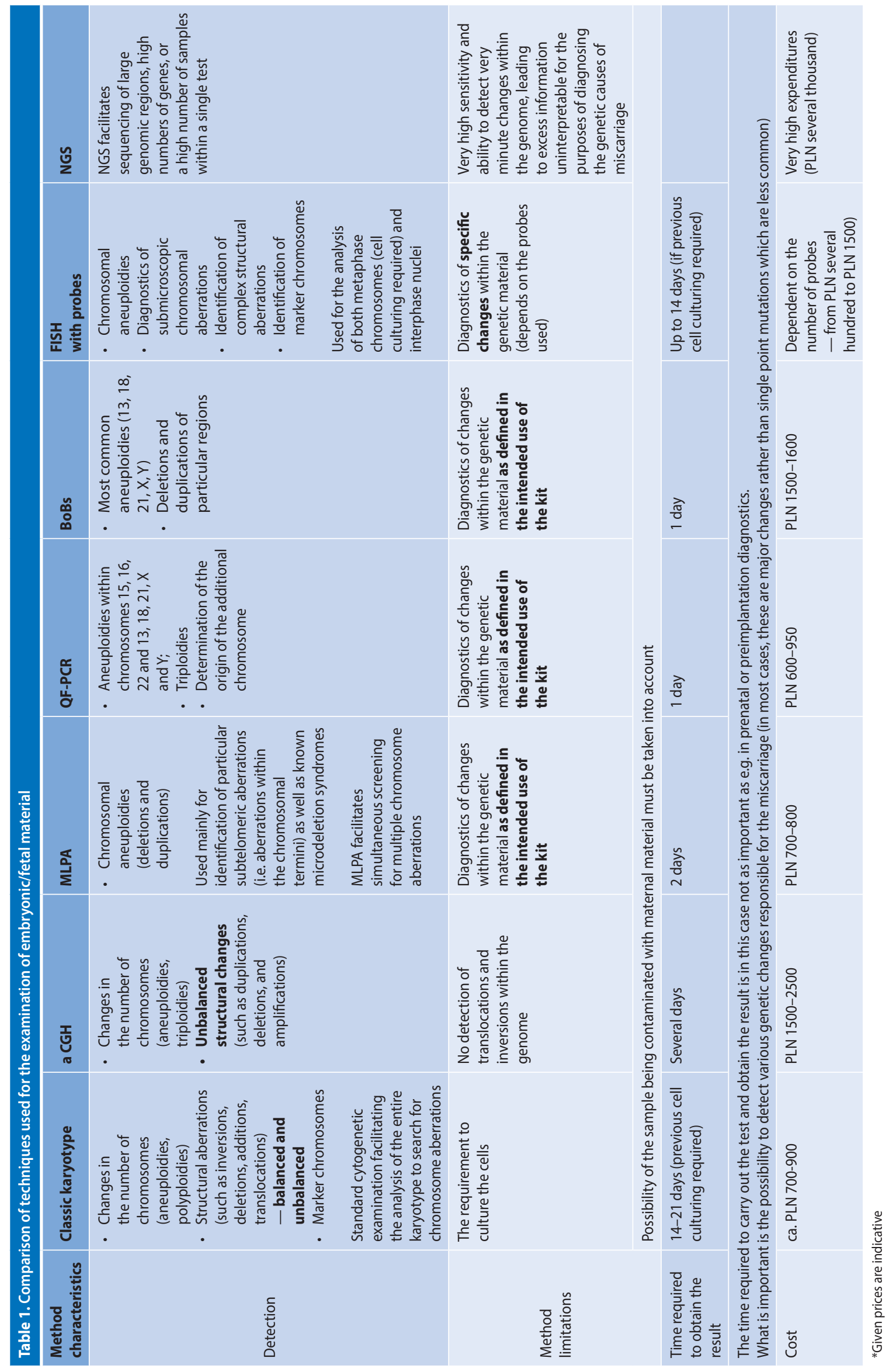




\section{REFERENCES}

1. Dória S, Carvahlo F, Ramalho C, [et al.]. An efficient protocol for the detection of chromosomal abnormalities in spontaneous miscarriages or foetal deaths. Eur J Obstet Gynecol Reprod Biol. 2009, 147, 144-150.

2. Rai R, Regan L. Recurrent miscarriage. Lancet. 2006, 68, 601-611.

3. Stirrat GM. Recurrent miscarriage. Lancet. 1990, 336, 673-675.

4. Royal College of Obstetricians and Gynaecologists (RCOG) (April 2011). "The investigation and treatment of couples with recurrent first-trimester and second-trimester miscarriage". Green-top Guideline No. 17. Royal College of Obstetricians and Gynaecologists (RCOG).

5. Practice Committee of the American Society for Reproductive Medicine. Definitions of infertility and recurrent pregnancy loss: a committee opinion. Fertil Steril. 2013, 99: 63.

6. Everett $C$. Incident and outcome of bleeding before the 20th week of pregnancy: prospective study from general practice. BMJ. 1997, 315, 32-34.

7. Sugiura-Ogasawara M. Recurrent pregnancy loss and obesity. Best Pract Res Clin Obstet Gynaecol. 2015, 29, 489-497.

8. Stephenson MD, Sierra S. Reproductive outcomes in recurrent pregnancy loss associated with a parental carrier of a structural chromosome rearrangement. Hum Reprod. 2006, 21, 1076-1082.

9. de Braekeleer M, Dao TN. Cytogenetic studies in couples experiencing repeated pregnancy losses. Hum Reprod. 1990, 5, 519-528.

10. Allison JL, Schust DJ. Recurrent first trimester pregnancy loss: revise definitions and novel causes. Curr Opin Endocrinol Diabetes Obes. 2009, $16,446-450$.

11. Kedar $\mathrm{P}$, Warang $\mathrm{P}, \mathrm{G}$ hosh $\mathrm{K}$, [et al.]. Recessive congenital mrthemoglobinemia due to $\mathrm{NADH}$-cytochrome b5 reductase deficiency associated with recurrent early pregnancy loss (REPL) in an Indian family. Ann Hematol. 2012, 91, 1985-1986.

12. Ciara E, Popowska E, Piekutowska-Abramczuk D, [et al.]. SLOS carrier frequency in Poland as determined by screening for Trp151X and Val326Leu DHCR7 mutations. Eur J Med Genet. 2006, 49, 499-504.

13. Argov $Z$, de Visser $M$. What we do know about pregnancy in hereditary neuromuscular disorders. Neuromuscul Disord. 2009, 19, 675-679.

14. Shore RN, MacLachlan TB. Pregnancy with myotonic dystrophy: course, complications and management. Obstet Gynecol. 1971, 38, 448-454.

15. Dufour P, Berard J, Vinatier D, [et al.]. Myotonic dystrophy and pregnancy. A report of two cases and a review of the literature. Eur J Obstet Gynecol Reprod Biol. 1997, 72, 159-164.

16. Bałajewicz-Nowak M, Pityński K, Milewicz T. Polimorfizm 1691 G > A (czynnik Leiden) i 1328T > C genu V czynnika krzepnięcia a występowanie poronień nawracających. Ginekol Pol. 2015, 86, 46-52.
17. Barlik M, Seremak-Mrozikiewicz A, Wolski $\mathrm{H}$, [et al.]. The -323P0/P10 factor VII gene polymorphism and the risk of recurrent miscarriage. Ginekol Pol. 2014, 85, 594-599.

18. Goodman CS, Coulam CB, Jeyendran RS, [et al.]. Which thrombophilic gene mutations are risk factors for recurrent pregnancy loss? Am J Reprod Immunol. 2006, 56, 230-236.

19. Coulam CB, Wallis D, Weinstein J, [et al.]. Comparison of thrombophilic gene mutations among patients experiencing recurrent miscarriage and deep vein thrombosis. Am J Reprod Immunol. 2008, 60, 426-431.

20. Udry S, Aranda FM, Latino JO, [et al.]. Paternal factor V Leiden and recurrent pregnancy loss: a new concept behind fetal genetics? J Thromb Haemost. 2014, 12, 666-669.

21. Coulam CB, Jeyendran RS, Fishel LA, [et al.]. Multiple thromophilic gene mutations rather than specific gene mutations are risk factor for recurrent miscarriage. Am J Reprod Immunol. 2006, 55, 360-368.

22. Yousefian E, Kardi MT, Allahveisi A. Polymorphism in Iranian women with idiopathic recurrent pregnancy losses. Iran Red Crescent Med J. 2014, 16.

23. Andraweera PH, Dekker GA, Jayasekara RW, [et al]. The obesity-related FTO gene variant associates with the risk of recurrent miscarriage. Acta Obstet Gynecol Scand. 2015, 94, 722-726.

24. Goddijn M, Leschot NJ. Genetic aspects of miscarriage. Baillieres Best Pract Res Clin Obstet Gynaecol. 2000, 14, 855-865.

25. Simpson JL. Causes of fetal wastage. Clin Obstet Gynecol. 2007, 50, 10-30

26. Carvalho B, Dória S, Ramalhob C, [et al.]. Aneuploidies detection in miscarriages and fetal deaths using multiplex ligation-depentent probe amplification: an alternative for speeding up results? Eur J Obstet Gynecol Reprod Biol. 2010, 153, 151-155.

27. Kwinecka-Dmitriew B, Zakrzewska M, Latos-Bieleńska A, [et al.]. Częstość występowania aberracji chromosomowych w materiale z poronień. Ginekol Pol 2010, 81, 896-901.

28. Hassold T, Chiu D. Maternal age-specific rates of numerical chromosome abnormalities with special reference to trisomy. Hum Genet 1985, 70, 11-17.

29. Kim JW, Lyu SW, Sung SR, [et al.]. Molecular analysis of miscarriage products using multiplex ligation-dependent probe amplification (MLPA): alternative to conventional karyotype analysis. Arch Gynecol Obstet. 2015, 291, 347-354.

30. Lathi RB, Milki AA. Tissue sampling technique affects accuracy of karyotype from missed abortions. J Assist Reprod Genet. 2002, 19, 536-538.

31. Maslow BS, Budinetz T, Sueldo C, [et al]. Single-Nucleotide Polymorphism-Microarray Ploidy Analysis of Paraffin-Embedded Products of Conception in Recurrent Pregnancy Loss Evaluations. Obstet Gynecol. 2015, 126, 175-181.

32. Kudesia R, Li M, Smith J, [et al.]. Rescue karyotyping: a case series of array-based comparative genomic hybridization evaluation of archival conceptual tissue. Reprod Biol Endocrinol. 2014, 312, 19. 